\title{
Artelogie
}

Recherche sur les arts, le patrimoine et la littérature de l'Amérique latine

5 | 2013

Femmes créatrices en Amérique latine : le défi de synthétiser sans singulariser

\section{Entrevista a Laura Malosetti}

Deborah Dorotinsky Alperstein y Laura Malosetti

\section{CpenEdition}

Journals

Edición electrónica

URL: https://journals.openedition.org/artelogie/5862

DOI: 10.4000/artelogie.5862

ISSN: 2115-6395

Editor

Association ESCAL

Referencia electrónica

Deborah Dorotinsky Alperstein y Laura Malosetti, «Entrevista a Laura Malosetti», Artelogie [En línea], 5 | 2013, Publicado el 16 octubre 2013, consultado el 20 diciembre 2021. URL: http://

journals.openedition.org/artelogie/5862 ; DOI: https://doi.org/10.4000/artelogie.5862

Este documento fue generado automáticamente el 20 diciembre 2021.

Association ESCAL 


\title{
Entrevista a Laura Malosetti
}

\author{
Deborah Dorotinsky Alperstein y Laura Malosetti
}

\section{NOTA DEL EDITOR}

La entrevista que abajo se presenta es el resultado de una serie de interrogantes que la Dra. Ana Paula Simioni y la que suscribe intercambiamos en el transcurso de un mes. (Entrevista realizada por Skype 11 de junio 2013, transcrita por Aline Chapa, maestría en en Historia del Arte, UNAM.)

Deborah Dorotinsky: ¿¿Cómo empezaste a interrogarte sobre los problemas de género en las artes y en tu trabajo con el arte Argentino del siglo XIX y de principios del XX? ¿Hubo algún 'detonador' intelectual o político particular?

Laura Malosetti: Bueno, el detonador para preguntarme por el género vino cuando empecé a estudiar en la Facultad. Durante la dictadura, yo conseguí un trabajo, tú te vas a reír, pero conseguí un trabajo con los primeros sexólogos de la Argentina (Laura Caldiz y León Roberto Gindin) que traían toda la teoría sexológica de California y que en un momento de muchísima represión sexual, además de todo tipo de represión, claro. Empezaron a trabajar en programas educativos además de terapéuticos, y en los medios; fueron las primeras intervenciones feministas en temas de sexualidad. Yo les traducía el material. Ellos tenían un posgrado para psicólogos, psicoanalistas y médicos en temas de sexualidad y en ese posgrado me ofrecieron dar clases sobre arte y sexualidad. Yo empecé a buscar dónde estudiar esos temas y ahí me encontré con bibliografía sobre historia del erotismo y los primeros textos de teoría e historia del arte feminista. Ahí fue que yo conocí a Griselda Pollock, su primer libro con Rozsika Parker: Old Mistresses ${ }^{1}$. Y conocí los textos de Linda Nochlin, en primer lugar el anuario de Art News de 1972, que editó con Thomas B. Hess: Woman as Sex Object, donde estaba su artículo Eroticism \& Female Imagery in Nineteent-Century Art. Leí también la Historia de la Sexualidad de Michel Foucault, a Georges Bataille, a Lo Duca... y yo hablaba de eso para los psicoanalistas, y mientras tanto hacía mi carrera. Más tarde pude incorporar lecturas feministas en la cátedra de Historiografía de las Artes Visuales, donde trabajé como docente. 
DD: ¿Qué estabas haciendo? ¿Tu licenciatura en Historia del Arte? 
1 LM: Sí, en la Facultad de Filosofía y Letras de la UBA. Empecé en los últimos años de la dictadura militar y viví todo el proceso de recuperación de la democracia y el regreso de profesores a la Universidad, la institución de un nuevo plan de estudios y becas de investigación para estudiantes y graduados jóvenes. Volvió entonces José Emilio Burucúa de Italia y fue mi director. Yo quería una beca para estudiar este mismo tema: Erotismo y Sexualidad en el Arte. Burucúa me dijo que veía muy difícil que me dieran una beca para trabajar sobre eso y entonces tomé un tema más amplio que era como "Resignificación de

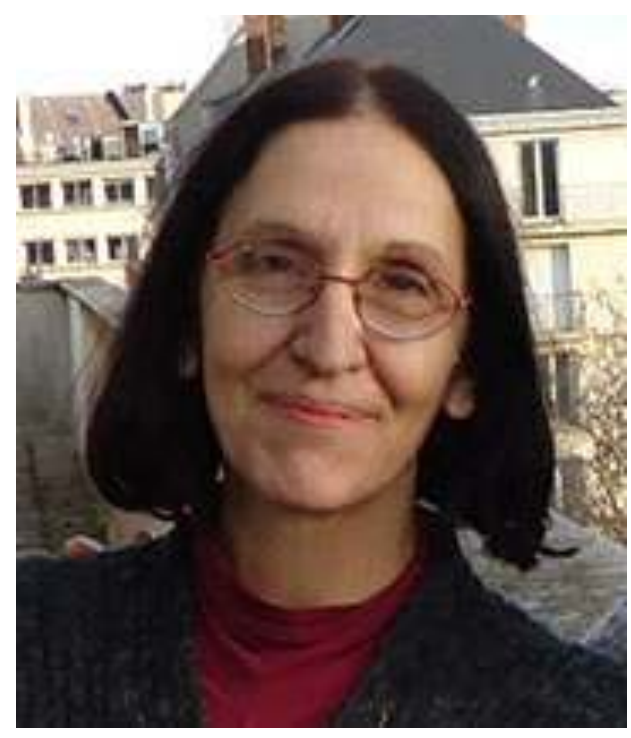
las imágenes y motivos iconográficos europeos en América Latina", un tema muy Warburgiano. $\mathrm{Y}$ de todo ese mapa enorme de cosas que se me presentaban como posibles vías de trabajo (entre ellas el paisaje) terminé volviendo sobre mi interés inicial: encaré la cuestión del erotismo de los raptos de cautivas, sexo y violencia, que es ese trabajo que publiqué en el coloquio del Instituto de Investigaciones Estéticas de la UNAM en Zacatecas, que fue la primera vez que yo salí de Argentina para presentar un proyecto en un congreso. ${ }^{2}$

DD: entonces al Coloquio del Instituto realizado en Zacatecas lo identificas como un parte aguas importante en tu reflexión sobre problemas de género en la plástica...

LM: Sí. De ahí en más, siempre seguí interesada no tanto en arte de mujeres, sino en esa lectura desde una perspectiva de género de los productos culturales. Poco después de que se abriera la democracia, se abrió el área de estudios de género en la Facultad de Filosofía y Letras de la UBA, que era muy fuerte en las áreas de historia, filosofía y letras, pero en el área de artes plásticas éramos muy pocas: dos investigadoras que venían de México: Ana Amado en estudios de cine y Mercedes Naveiro, que trabajaba sobre Leonora Carrington y Remedios Varo, y yo.

DD: En las historias canónicas del Arte decimonónico en América Latina parecería que hubo pocas mujeres artistas que estuvieron activas. La investigación en este campo de unos años a la fecha ha demostrado lo contrario, pero cabe preguntarse con qué factores se vinculó esta común invisibilización: ¿tiene que ver con las condiciones de formación de las artistas? ¿O está relacionado con un reconocimiento más bien póstumo? ¿O quizás tenga que ver, con la manera de producir de éstas artistas? ¿O se refiere más bien al tipo de objetos que estaban produciendo estas mujeres?

LM: Creo que esto se vincula con un contexto más general en dos sentidos. Por un lado, hasta las últimas décadas del siglo XIX en América latina hay muy pocos centros de actividad artística organizados - salvo México y en alguna medida Brasil, que tuvieron academias tempranas. Más bien hay artistas que trabajan, y siguen produciendo pintura religiosa o trabajan haciendo retratos y se empiezan a formar las academias. Y por otro lado, también con un contexto más general que tiene que ver con el lugar de la mujer en esas sociedades. Aun cuando hubiera mujeres artistas, éstas no tuvieron visibilidad ni oportunidades más que como discípulas, ayudantes o 
diletantes. Vos pensá que los primeros movimientos feministas en Buenos Aires, por ejemplo, son de fines del XIX.

DD: ¿Pero eran movimientos feministas, Laura, o movimientos sufragistas, que no es exactamente igual?

LM: Claro, sí, sufragistas pero también hay movimientos de mujeres que se organizan y plantean demandas en el campo de la educación, por ejemplo, desde mediados del siglo XIX, demandas de derechos civiles, reivindicaciones laborales como la huelga de empleadas domésticas de 1888, o las huelgas de conventillos con importante participación de mujeres. A fines del siglo XIX hay un enorme cambio en la sociedad argentina, hubo un Centro Socialista Femenino, agrupaciones femeninas anarquistas, también es el momento en que se forman las primeras mujeres universitarias, médicas, pero claro, esos derechos civiles sólo van a ser obtenidos en las primeras décadas del siglo XX. En este sentido, si bien había una enorme cantidad de mujeres que se dedicaban a pintar o a hacer arte, ese arte, prácticamente a todo lo largo del siglo fue visto o bien como "labores femeninas", como labor de mujeres para calmar los nervios y escapar a la rutina doméstica; o bien [como] el adorno a las señoritas ricas: para tener una formación más completa estudiaban piano, pintura, bordado. Sin embargo hubo mujeres artistas que transgredieron esas pautas, como Sofía Posadas, que pintó desnudos y los expuso en el Salón del Ateneo, y generó una gran polémica en los diarios. En Buenos Aires se tematizó mucho esta cuestión, porque no te olvides que acá hay un campo literario muy temprano y muy destacado de mujeres que se dedican a las letras: mujeres como Mariquita Sánchez de Thompson que ya temprano en el siglo XIX tienen una actividad intelectual muy fuerte. Aparecen artículos de diarios que decían que las mujeres mejor se dedicaran a pintar que a las letras porque las letras las volvían más peligrosas, que era como una ocupación menos peligrosa para la inserción de las mujeres en la sociedad.

DD: No querían que las mujeres se volvieran del tipo de las bas bleu francesas ni que tuvieran ideas subversivas...

LM: Exacto, pero siempre las tuvieron.

DD: $Y$ cuando llegamos ya...

LM: Perdón, por ejemplo había tipos de arte muy de mujeres como la miniatura. El retrato en Buenos Aires tenían una buena cantidad de mujeres que se dedicaban a eso, o la pintura sobre porcelana, pero también la pintura al óleo.

DD: Claro, y escultoras las menos...

LM: Las menos. La primera escultora y que es un caso muy notable en Argentina es Lola Mora, que fue una mujer, digamos, notable en muchos sentidos y siempre se redujo el análisis de su figura a la biografía, como se ha hecho tantas veces...

DD: Y poco al análisis de su obra y de su producción y la forma en que estas obras circulaban.

LM: Exacto, si. Hace poco que algunas jóvenes historiadoras de arte han encarado el trabajo sobre su obra desde otras perspectivas.

DD: ¿Y tenían circulación las obras de estas mujeres, Laura, al exterior de la familia?

LM: Mira, en Buenos Aires, (estamos hablando de Argentina), las mujeres tenían un lugar como alumnas de los pintores y como organizadoras de exposiciones, mecenas. Tampoco es que había tantísimo trabajo para los pintores. Ellos se dedicaban a dar clases y el $\mathbf{9 0 \%}$ de los alumnos eran alumnas, pero no bien se empiezan a hacer 
salones, en las últimas décadas del siglo, la mujeres exponen y en algunos casos son casi el $50 \%$ de los expositores.

DD: Y está registrado eso en los salones de las academias. ¿Pero eran exposiciones para mostrar obra como los profesores de pintura pudieron haber expuesto aquí a las San Román, por ejemplo, los profesores de las academias que daban clases particulares a las señoritas y a las señoras o eran exposiciones con venta al público ?

LM: Por un lado estaban las exposiciones de los talleres, pero cuando se empiezan a hacer las primeras exposiciones públicas acá en Buenos Aires desde el Ateneo en la década de los 90, las mujeres compiten como los hombres. Por supuesto no ganan premios, no se adquieren mucho sus obras, pero exponen. Algunas de ellas viajan a Europa y llegan a exponer en el Salón de París, como María Obligado de Soto y Calvo o Diana Cid.

DD: Y pasando ya a la vanguardia latinoamericana de principios del siglo $X X$, de los años 20, tenemos muchas mujeres artistas que se destacan. Tenemos a Tarsila do Amaral, a Frida Kahlo, a María Izquierdo, Nora Borges. ¿Como puedes explicar la presencia de estas mujeres, digamos, como en una página importante de la historia del arte de la vanguardia moderna - no modernista, moderna- y el reconocimiento que recibieron.? ¿Tu crees que había mayor permeabilidad al éxito de las mujeres en esos ámbitos? ¿que puede haber tenido algo que ver con las ideas sobre las "nuevas mujeres" en estos años de la entre guerra en Europa?

LM: Sí, en parte sí, las mujeres de la elite. Las capitales latinoamericanas estaban muy conectadas con Europa y creo que esa permeabilidad mayor que se produjo en la Europa de entreguerras también permeó la escena latinoamericana. No te olvides, por ejemplo, que Nora Borges era hermana de Borges, o sea que tiene una entrada a esos círculos intelectuales privilegiados. Y por otra parte, la figura de Nora Borges fue revalorizada muy tarde, a la sombra de las grandes figuras del momento, de su hermano, de Bioy... Por otro lado tienes una figura como la de Raquel Forner que nunca jamás se reivindicó como mujer artista, ni como feminista, mas bien quería entrar en el campo como artista tout court.

DD: De acuerdo, pero vamos a tomar el ejemplo de otras mujeres artistas sobre las que has escrito en algún momento. Emilia Bertolé: Julia Wernicke, Lía Correa Morales de Yrrurtia, Diana Cid y algunas más. ¿Tu crees que, el trabajo de estas mujeres y su rescate, tuvieron alguna incidencia en el trabajo de mujeres artistas en la segunda mitad del siglo XX en Argentina.? ¿Se llegó a pensar en algún momento en algo como un "canon de arte femenino" o algo semejante por parte de las mujeres artistas de la segunda mitad del XX?

LM: No, hasta donde sé. Yo te diría más bien que la figura de esas mujeres quedó completamente soslayada en la historia del arte, aún incluso cuando ahora se está empezando a trabajar sobre la figura de ellas. Yo estuve rescatando muchas noticias sobre los escándalos que se generaron en el XIX y las polémicas, y hay algunas personas que se han formado conmigo que están trabajando sobre ellas. En Rosario se rescató la figura de Emlila Bertolé. Pero no conozco mujeres artistas que hayan tomado esa bandera, por decirlo así, sino que más bien es una construcción nueva. No conozco mujeres artistas contemporáneas que estén trabajando sobre aquellas mujeres del siglo XIX. Y yo te diría que la recuperación de las cuestiones de género en el siglo XIX, que las hay y las ha habido, ha sido por parte de artistas varones y esto me parece interesante, porque son artistas varones que han trabajado a partir de textos de historiadores. Alberto Passolini es un ejemplo bien interesante porque Passolini tuvo la muestra de arte contemporáneo en MALBA para el Bicentenario. Él hace una lectura de género que podríamos decir es desde un punto queer, no sé 
exactamente si ponerle ese nombre, pero una lectura a contrapelo. Primero trabajó sobre los desnudos de Prilidiano Pueyrredón. Hizo una muestra que se llamó "Señorito rico", como desarmando esa mirada masculina sobre los desnudos en el XIX y para el Bicentenario en MALBA hizo una muestra que se llamaba "Malona", que era tomar el tema de las cautivas al revés, y hacer un malón de chicas que se robaban a un rubiecito. Trabajó sobre el deseo femenino. Una muestra realmente muy linda. También podría mencionar a Fermín Eguía, que reflexiona a partir de "El despertar de la criada", el cuadro escandaloso que pintó Eduardo Sívori en 1887, sobre el lugar del voyeur en una serie de obras ${ }^{3} \mathrm{y}$ otros artistas como Daniel Santoro o Leonel Luna que también subvierten iconografías del siglo XIX, o Tomás Espina que se pone él mismo, desnudo, en el lugar de la mujer en "Sin pan y sin trabajo" de Ernesto de la Cárcova, (1894) pero son todos varones.

DD: entonces ¿cómo explicarías un concepto como el de intervenciones feministas en la Historia del Arte si estas intervenciones de reflexión sobre la construcción de género la están haciendo los varones?

LM: No me produce ningún ruido eso, en el sentido de que son miradas críticas sobre la economía de los géneros que las producen varones, yo creo que la mirada crítica sobre las relaciones de género, clase, raza no son exclusivas de las mujeres. Digamos, el pensamiento crítico o el desarmar prejuicios respecto de estas cuestiones no tiene necesariamente que venir sólo de las mujeres. Por supuesto que no estoy nombrando aquí a todas las artistas contemporáneas que trabajan críticamente cuestiones de género desde otros lugares, incluso también en sus encrucijadas con la política y los derechos humanos. Sólo mencionaba a quienes retoman cuestiones del siglo XIX.

DD: Y en ese sentido en particular tu trabajo sobre "La Vuelta del Malón" a mí me llama la atención porque abordas temas -en ese trabajo del Coloquio de Zacatecas de 1993-de género, de raza, de clase social, pero también de espacios, como espacios de la nación. ¿Cómo vinculas en otros trabajos tuyos o en otras obras que has abordado, esta situación, quizás como "engendrados", como si estos espacios naturales de la nación tuvieran un género también? ¿Tienes otras obras donde abordes estos lugares como la Pampa, donde tienes esa mirada que teje juntos estos temas que son particularmente claves para el arte latinoamericano?

LM: Yo creo que esa línea, ese lugar de la mirada está en todas las cosas que estoy trabajando siempre... por ejemplo ahora estoy trabajando sobre retratos de los héroes y estoy haciendo una mirada comparativa entre estas figuras de los héroes con aquéllos y aquéllas que tomaron parte en la emancipación o la formación de las naciones y que no tuvieron retratos. Analizando qué características tienen los retratos de género y clase, y también la ausencia de retratos de mujeres en esos panteones nacionales y cómo funcionaron, por ejemplo en Chile, los retratos de Javiera Carrera en relación con estas representaciones. Pero también me parece interesante pensar todo esto en relación con el fin de la última dictadura militar donde sí hubo intervenciones femeninas muy fuertes e intervenciones de varones queer muy fuertes y la cuestión de la sexualidad y el género apareció como un gesto contestatario en términos de subversión de un orden establecido que había imperado durante la dictadura. Acá estoy pensado en los primeros tiempos del "Rojas", cuando se abre este espacio Centro Cultural Ricardo Rojas, que es de la Universidad de Buenos Aires. Ahí está la figura de Batato Barea, la figura de Marcia Schvartz y su hermana, haciendo performances, de Liliana Maresca y de artistas varones que trabajan estéticas que fueron consideradas femeninas. Parece que ese nudo todavía 
hay que terminar de desatarlo, pero allí hubo una operatividad muy fuerte de las cuestiones de género en relación con la política, con la apertura política, que han sido leídas en general como una despolitización del arte.

DD: Eso me da pie a dos preguntas más. Por un lado, quiero preguntarte sobre una suerte de doble militancia. En este periodo de la dictadura argentina los artistas y las artistas estaban trabajando por un lado en un discurso feminista, o por el lado de los discursos de los movimientos queer, con el mismo trabajo intentaban incidir en una política en contra del régimen militar. ¿Cómo se dieron estas dobles militancias? ¿Como ves tú que podían mediar o no los artistas entre estas dobles posturas?

LM: Por un lado hubo un movimiento feminista que, como te decía, se dio más que en las artes plásticas, en las letras y también en el ámbito del cine. La figura de María Luisa, de Sara Facio y la organización de festivales de "La mujer y el cine" o la revista Feminaria, que empezó a publicarse en 1988, la creación del Instituto de Estudios de Género en la UBA, la publicación de la revista Mora, etc.; pero, por otro lado, también me parece, por ejemplo, que las marchas del orgullo gay fueron unas marchas muy importantes en las que se puso en juego este doble efecto de una estética politizada y una estética queer, incluso también feminista, es decir, se mezclaba todo en esas marchas y se ponía además en la calle toda una estética. Hay grupos de artistas como el GAC (Grupo de Arte Callejero) y sobre todo Mujeres Públicas que llevan adelante esa doble militancia hoy. También estoy pensando en el movimiento que se hizo para hacer las primeras exposiciones de arte erótico que organizó León Ferrari en el Centro Cultural Recoleta. León hizo caligrafías de textos tremendos de la iglesia contra las mujeres como objetos sexuales de perdición, sobre torsos femeninos de maniquíes, impactantes. El Centro Recoleta fue muy importante cuando abrió después de la dictadura. Y creo que toda esta cosa del desparpajo... había una represión sexual muy fuerte en esos años, un peso muy fuerte de la iglesia católica, un peso muy fuerte del discurso represivo y yo no te voy a decir que hubo un destape a la española, pero sí hubo todas estas manifestaciones que en el terreno de las artes plásticas merecen una lectura de género crítica, que en parte se ha aplicado a figuras como Batato Barea, Liliana Maresca, Marcia Schvartz o Pablo Suárez.

DD: Yo quería volver a la figura de Marcia Schvartz. En un artículo tuyo sobre Marcia tú afirmas y relatas, que la obra que trabaja Marcia era una obra para sí, que el tipo de retrato que está haciendo Marcia era más bien una especie de indagación. A mi me llama mucho la atención porque es otra cosa que noto yo en el caso de las fotógrafas, en la insistencia sobre el género del retrato. Muchas artistas visuales como Cindy Sherman, Nan Goldin, la propia María Izquierdo, la misma Frida Kahlo, como caso paradigmático, recurren mucho al manejo del retrato. ¿Cómo vincularías esta construcción de género con las construcciones de los géneros artísticos? A mí me parece que quizás el retrato ocupa un lugar muy particular como dispositivo para indagar en estas dobles construcciones, pero quiero saber tu opinión al respecto.

LM: Sí, absolutamente de acuerdo. Yo creo que el retrato y también en buena medida el autorretrato. Y esto tiene que ver con poner el cuerpo. Yo creo que hay en las artistas una conexión con el cuerpo, aunque no quiero generalizar, con el propio cuerpo y con el cuerpo de los otros como el lugar de reflexión importante. Incluso la idea de trabajar los retratos en relación con una mirada intimista sobre los sujetos. Una mirada con un discurso no autoritario. Estoy pensando no sólo en Marcia, que tiene una empatía muy fuerte con Batato Barea, por ejemplo, e incluso en su mirada sobre ella misma, (ese autorretrato donde ella se hace una raya roja en la cara). Son como retratos heridos, que vinculo, por ejemplo, con la obra de Graciela Tacchini, 
una videoartista que siempre trabaja sobre su propia imagen; hizo una obra que se llama "Rota" que era como otro modo de reflexionar sobre sí misma. Creo que hay un privilegio del discurso sobre sí mismas en muchas artistas, como Liliana Maresca que se hace fotografiar con un cartel que dice que está apta para todo servicio y ofreciendo su cuerpo. Y te podría poner muchos otros ejemplos en los que el propio cuerpo aparece como soporte de un discurso antiautoritario. Es decir "Yo pongo mi cuerpo porque soy vulnerable" y es como un llamado a la vulnerabilidad y una lectura de la vulnerabilidad de los otros. Pienso también por ejemplo en esta excelente fotógrafa que se llama Adriana Lestido y que trabaja con madres presas, con los niños del hospital infantojuvenil. ${ }^{4}$ Y La mirada de Adriana Lestido es una mirada impresionante, indescriptible, de una gran captación no declamatoria.

DD: Claro, es como el trabajo de Vida Yovanovich ${ }^{5}$ sobre las ancianas: muy empático, pero a la vez muy desnudo también, ¿no? Confrontativo...

LM: Si... Hay una fotografía emblemática de Adriana Lestido donde una chica presa está abrazando a su bebé con todos sus brazos tatuados y una expresión desafiante, mirando para el costado, como diciendo "yo estoy protegiendo a mi cría" y es un retrato de una fuerza impresionante, y ella no connota, no opina, ella te la presenta así. Me parece que para ese tipo de discurso el retrato se presta mucho más allá de lo evidente. Por otra parte, desde el siglo XIX el género del retrato fue ocupación de muchas mujeres, incluso estoy pensando en los retratos de corte que hacían artistas mujeres como Vigée Lebrun en el siglo XVIII.

DD: Claro, desde el Renacimiento, de hecho.

LM: Sí, era como una ocupación de mujeres. Pero yo creo que hay un uso subversivo de ese género también. Tal vez porque es tradición también, ¿no?

DD: Como algo muy manejado, muy cercado, la parte del canon que se les permitió a las mujeres artistas

LM: si si, puede ser...

DD: Bueno, hablamos del XIX, hablamos un poco de las vanguardias, hemos hablado de cosas más contemporáneas...

LM: Otra cosa respecto de los retratos, que no es sólo un espacio de producción permitido. Yo creo que también, en el mapa general, cuando uno se propone ser artista y decir algo, todo artista quiere entrar en el canon, artista hombre o mujer. $Y$ yo creo que esa búsqueda de la voz propia debe ser algo tremendamente difícil y en esa búsqueda de la voz propia hay también una entrada en una cierta tradición de autorreflexión. No sé, esto es un pensamiento en voz alta

DD: Un poco como una cuestión de indagación "sobre sí", sobre uno mismo o una misma, pero también como una forma de acercarse a obtener un mecenazgo ya sea privado o del Estado, mecenas de arte y de indagar sobre los otros. Sería como plantear una tradición que va a contrapelo de la tradición del retrato honorífico, en el fondo...

LM: Exacto, si sí.

DD: Esto para el caso del arte más bien figurativo. Lo que nos pasa con este periodo ¿qué le ocurre a la producción plástica de las mujeres artistas cuando triunfan los lenguajes abstractos ? Hay muchos teóricos y muchos historiadores del arte y algunas historiadoras del arte feministas que insisten que entre la década del 40 y el 60 del siglo XX realmente el arte abstracto impuso mayores barreras para las mujeres artistas. ¿Sería ese el caso de América Latina en general o para Argentina ? ¿qué relación tendría el asunto del cambio del 
lenguaje hacia la abstracción y la posición de el género o la construcción de problemas de género?

LM: Yo no sé. No generalizaría tanto porque pensar que en América Latina una mujer como Gego ${ }^{6}$ en Venezuela que verdaderamente es una de las artistas más importantes del continente... O Lygia Clark en Brasil, Pero hubo mujeres en los movimientos abstractos de Chile, como Matilde Pérez o Sara Malvar. En Argentina, el movimiento del arte concreto también incluyó mujeres. Estoy pensando en Lidy Prati, por ejemplo. No sé si es un período tan acusadamente viril. No lo tengo muy claro, tal vez es cuestión de poner otra mirada sobre el período, pero por otra parte, cada lugar tuvo sus peculiaridades. Por ejemplo, en el arte chileno en la escultura y grabado ha habido una presencia importante de mujeres. Las grandes escultoras chilenas como Lily Garafulic o Rebeca Matte y por ejemplo grabadoras como Roser Bru.

DD: Igual que en México tienes mujeres destacadísimas que trabajaron el tapiz y no hay hombres tan sobresalientes que lo trabajaro. Estoy pensando en piezas de Marta Palau, en particular.

LM: En Argentina también, las tapicistas más importantes son mujeres. Pienso en Nora Correas, Gracia Cutuli, Nora Aslan entre ellas. (Pero además escultoras destacadas que han sido poco estudiadas como Alicia Penalba o María Juana Heras Velasco).

DD: Me parece importante ésta reflexión que estás proponiendo sobre la no generalización. ¿Encuentras tú, que hay una diferencia en el discurso de las y los académicos ocupados hoy en día en la construcción de género en las artes visuales, del discurso de nuestros colegas o nuestros pares de Inglaterra o en los Estados Unidos o incluso en Francia ? ¿Por otra parte al interior de nuestro mismo gremio qué diferencias existen entre nosotros? ¿Cómo partimos para articular una experiencia común y cómo a la vez expresamos nuestras particularidades?

LM: Es una pregunta difícil, en general nosotros leemos teoría construida en Europa y Estados Unidos y ahí hay como una economía mundial casi indestructible. Igual nosotros en América Latina tenemos teóricas de género importantes como Nelly Richard. Creo que por otra parte, hay algo distintivo en AL que es el cruce de problemas: Yo sostengo una lectura de género como relación de poder al interior de la sociedad y, en este sentido, el cruce entre género, raza y clase en AL tiene sus peculiaridades y creo que esto está siendo recuperado tanto en la academia y también por parte de los artistas mujeres y hombres y, en este sentido, hay cada vez más jóvenes que están dedicándose a estudios de género. El área de género en la Universidad de Buenos Aires creció enormemente, hoy es un área para el doctorado. En la universidad de San Martín también hay un departamento de estudios de género importante y se está trabajando género sobre la escena contemporánea. Y también se están llevando adelante etapas que en EU y en Europa se realizaron hace mucho, pero que acá no se habían hecho como es el caso de la recuperación de artistas mujeres. Acaba de publicarse el libro de Gloria Cortés Aliaga en Chile. Y el de Ana Paula Simioni en Brasil no tiene tantos años ${ }^{7}$. Acá en Argentina hay una historia de mujeres fotógrafas ${ }^{8}$, pero no hay una historia de mujeres pintoras todavía. Están trabajando dos becarias en eso, Julia Ariza y Georgina Gluzman, tú las conociste en Austin.

DD: Hay una tendencia en la historia feminista del arte de decir: "no se trata de recuperar artistas por kilo o por metro, sino más bien hablar de intervenciones y no reproducir el discurso jerárquico y dominante del canon". ¿Cómo ves tú estas producciones que son de 
alguna manera una suerte de rescates de las producciones artísticas de los márgenes del canon?

LM: Sí, yo estoy totalmente de acuerdo y así he trabajado. Sin embargo, esa tarea de recuperar nombres o de recuperar obra está iluminando zonas de la cultura que habían sido inexploradas, que tienen que ver no sólo con el lugar de las mujeres y su relación con el canon, sino con el canon mismo. Por ejemplo, Georgina Gluzman está encontrando que la mayor cantidad de obras de mujeres está en los museos históricos y no en los museos de arte porque ellas hicieron pintura patriótica. Esto es un tema raro, nuevo, digamos y que tiene que ver con qué pintura se consideraba arte y qué pintura se consideraba otra cosa, como ilustración. Yo creo que se abre a lugares insospechados. O el trabajo de Julia Ariza sobre los lugares de las mujeres en las imágenes de los diarios y revistas, y su rol en las academias de artes y oficios. Yo no estoy de acuerdo con la recuperación al kilo, pero sí me parece que la historia cultural merece una indagación acerca del lugar de las mujeres en distintos ámbitos de intervención. Esto mismo se ha hecho en el ámbito de las letras, con el estudio de las prácticas de lectura y el rescate de autoras que habían quedado por fuera del canon como Juana Manuela Gorriti, por ejemplo. No creo que por no haberse hecho en los 70 no se tenga que hacer. Y por otra parte, en la recuperación de la figura de mujeres artistas, hoy no va a ser el mismo gesto de decir "Bueno señores, la historia del arte ingresó estos nombres y los sumamos”, sino “a ver, hay otra historia del arte que se vincula con la cultura visual de la época, con la historia cultural y distintos lugares de intervención" y aquí hay toda una zona que quedó inexplorada.

DD: Justamente una forma de hacer historia del Arte que se acerca más a la forma de trabajar que José Emilio Burucúa rescató de Aby Warburg, algo que también se aprecia en tus textos. Entonces Laura, un trabajo histórico crítico de este cariz implica reflexionar sobre el canon como un problema, como una cuestión de construcción historiográfica problemática, y al mismo tiempo plantearse la posibilidad de que existan otras historias del arte en América Latina también. Hay que incluir en esta reflexión sobre la diversidad cultural y las multiplicidades de las historia del arte la diversidad de las historias del arte que se pueden generar a partir de las lecturas en clave de género. ¿Qué me dirías respecto al problema de "la muerte del autor" para la reflexión de género en la Historia del Arte?, Sobre todo a la luz de los trabajos de algunas feministas en el campo de las letras, quienes afirmar que sigue siendo importante identificar la autoría, sobre todo por que ayuda a visibilizar a las mujeres creadoras.

LM: Sí, no te olvides que nosotros estamos hablando de la muerte del autor en el arte contemporáneo pero también ocurre que hay una muerte del autor en la historiografía contemporánea. Hoy hay una recuperación de imágenes del pasado como insumos e incluso como plataforma crítica, que me parece que habilita esta reflexión acerca de las imágenes como por fuera del canon, como circulando salvajemente. Esto me parece muy seductor. El hecho de trabajar sobre la vida de las producciones culturales sin que necesariamente el fin sea encontrar una gran artista para agregar al canon argentino, sino bueno, estas imágenes estaban allí... Vuelvo sobre el caso de las mujeres que hacían ilustraciones históricas. Circulaban a millones, nadie sabía quién las había hecho, pero todo mundo las conocía y es muy interesante analizar cómo funcionaron esas imágenes e iluminar esas zonas de circulación de imágenes que no entraron en el canon, pero que sí educaron la sensibilidad de generaciones, o educaron la sensibilidad de los niños, o educaron nuestra propia sensibilidad a lo largo del tiempo. Me parece que este pensar el lugar 
de las imágenes en la vida social incorporando la perspectiva de género tiene muchísima tela para cortar.

DD: En esto coincido contigo. ¿Tu creerías que sería, por un lado, una construcción de "formas de ver", estas visualidades que están determinadas social, cultural, histórica, temporal, geográficamente, y por otro lado una manera también de antropologizar el discurso de la historia del arte?

LM: Totalmente, porque la verdad hoy el discurso de la historiador del arte tiene que salir de la construcción canónica, porque corre le peligro de quedarse aislado en su pequeño mundo dorado y que se le escape la cultura por el costado. En este sentido, la autonomización del mundo del arte genera una suerte de especialización de los historiadores del arte metidos adentro de esa cápsula, y que verdaderamente se vuelve peligrosa en el sentido de que el historiador pierde en buena medida la capacidad crítica que fue adquiriendo a lo largo del siglo XX con las tendencias más radicales, de Warburg a Timothy Clark y a Linda Nochlin y a Griselda Pollock, con la historia social del arte y la historia feminista. Toda esta batería de recursos yo creo que es necesario aplicarla a fenómenos que caen por fuera del canon o del mundo del arte, desde la historia de la moda, hasta la de la ilustración de libros, de las imágenes impresas en diarios y revistas, en fin, de toda esa circulación de imágenes que, por otra parte, hoy los artistas están usando como insumos. Hay muchos artistas que están trabajando sobre estos temas.

DD: De cultura de masas y cultura popular...

LM: Y tradiciones, y discursos heredados. Hoy hay una interpenetración muy grande de mundos imaginarios en la escena del arte.

DD: Tu consideras que en la sobras de las artistas mujeres contemporáneas, parece haber, como en el caso del la obra de Rosanna Paulino, Marcia Schvartz, Nicola Costantino, Silvia Contreras, una suerte de recusa del feminismo. ¿Qué pasa con estas artistas que evidentemente se acercan a las poéticas feministas, que evidentemente están abordando cuestiones feministas, o que se asocian a cuestiones feministas, pero en el que ellas insisten de alguna manera, incluso en afirmar contundentemente que no son artistas feministas ? Es decir, ¿cómo se pone en juego este doble discurso?

LM: Este doble discurso no es nuevo. Yo vi año tras año fracasar las exposiciones de mujeres que se organizaban para festejar el 8 de marzo, por ejemplo. Muchas artistas que rechazan tajantemente ser incluidas en el gueto de artistas mujeres y me parece razonable porque ahí sí hay una situación de replicar un canon creando como un para-canon.

DD: Claro, el gineceo artístico...

LM: Exacto, entonces hay como un ir al asalto, en estos casos que plantea Ana Paula son artistas agresivas, desafiantes, lo que se están planteando es "yo no hago arte de mujeres, no me importa nada, es más rechazo esta situación, en un punto parodio", hacen una parodia o una revisión crítica de estas posiciones.

DD: ¿Si, te parece que son una forma de revisión crítica?

LM: Sí yo creo que sí, aunque siempre es mucho más sencillo pensar una revisión crítica en palabras que en imágenes. Estas imágenes son muy ambiguas y por ejemplo, esta obra que hizo Nicola para la Bienal de Venecia9 .

DD: La de Evita...

LM: La de Evita, tan polémica. Ya viste que ahora hay una intervención del gobierno en la obra, ella está protestando. Bueno es una obra que, aunque parece muy llana, o 
sea como una mirada bastante plana de la figura de Evita; sin embargo, yo creo que reviste allí una visión crítica de esos lugares de género donde fue puesto el mito.

DD: Esto en cuanto la producción artística. Qué puedes decirme en cuanto a las prácticas curatoriales. ¿Existe tal cosa como una práctica curatorial feminista? ¿Qué tipo de muestras de curadurías ha habido de mujeres que te parezcan notables en tu visión realmente muy panorámica de lo que ocurre en América Latina, en la producción con temas de género y en particular con las mujeres artistas?

LM: En realidad, no te creas que tengo una mirada tan panorámica. Yo sé que en México ha habido exposiciones muy importantes y mi colega Karen Cordero ha curado algunas y sé que ha habido muestras desde los tempranos 60s de mujeres feministas. Aquí en Argentina, si bien hay muchas curadoras mujeres, son pocos los ejemplos que yo te podría dar de una curaduría que tengan un marcado carácter feminista. Ha habido curadurías que recuperan la figura de algunas mujeres. Pienso por ejemplo en la exposición que curó Adriana Lauria sobre Liliana Maresca, estuvo muy bien, fue una recuperación importante. La exposición Territorios de diálogo, de 2006, con curaduría de Rita Eder, Diana Wechsler y Jaime Brihuega sobre el arte de entreguerras, si bien no tuvo un marcado sesgo feminista, sí tuvo una mirada desde y sobre lo femenino en ese período de incertidumbre y zozobra. Y luego el trabajo curatorial sobre artistas contemporáneas, como la extraordinaria exposición de Liliana Porter en Recoleta curada por Inés Katzenstein en 2005, o la que hace Andrea Giunta con Graciela Sacco, pero por ejemplo la posición de Graciela Sacco tampoco es feminista, ni la de Forner, aunque su iconografía siempre sea femenina. Más allá de esos rescates, es difícil, yo te diría que no veo una práctica curatorial feminista muy destacada aquí.

DD: Sí aquí yo también encuentro problemática y algunas de las cosas que ha habido no han dado excelentes resultados Creo que en el caso del trabajo de Lorena Wölffer ha sido exitosa, pero porque me parece que en buena medida hay muchas cosas que están en manos de ella misma y que cosas que tienen que ver con el performance me parece que operan de otra manera.

LM: Claro, sí. Es el caso de una artista bien notable que es Marta Minujín, de ella se hizo una muestra en MALBA hace un par de años, importante también, con curaduría de Victoria Northoorn.

DD: ¿Y qué me dices del trabajo de las mujeres indígenas en Argentina, Laura? Esa es una de las cosas en las que nuestras realidades son, de pronto, tan abismalmente diferentes.

LM: Diferentes, sí. Bueno, mira, en general, las mujeres indígenas en distintas zonas de la Argentina han trabajado y trabajan en lo que se ha considerado artesanía, trazando esa frontera que Ticio Escobar cuestiona con tanta lucidez. Cerámica, tallas, pero sobre todo tejido y diseño textil. $\mathrm{Y}$ hay varias iniciativas en este sentido de asociación de diseño con técnicas tradicionales que llevan adelante algunas ONGs y ahora la Secretaría de Cultura, que me parecen importantes para socavar esas barreras.

Por otra parte, quisiera mencionar a Teresa Pereda, una artista que ha llevado adelante un proyecto: "Recolección / Restitución", viajando por América y trabajando con comunidades indígenas, con sus técnicas, materiales y mitos, haciendo cosas y acciones colectivas, en Tierra del Fuego, pero también en Bolivia y en Brasil.

También me gustaría mencionar algunos colectivos de artistas jóvenes excelentes que hay acá como el de Mujeres Públicas que hacen intervenciones en la calle. Este tipo de 
intervenciones me parecen muy valiosas. También son activistas como el GAC, Grupo de Arte Callejero. No están dentro del circuito, pero tienen intervenciones potentes. Nosotras hicimos una exposición de Historia de las Mujeres con Dora Barrancos, que es la historiadora de las mujeres en Argentina, y Mirta Lobato que es historiadora de mujeres trabajadoras. Entre las tres hicimos el guión para una exposición de la historia de las mujeres en Argentina. La curaduría la hizo Valeria González, que estuvo en el coloquio de fotografía ${ }^{10}$. El resultado fue muy interesante porque pusimos obras del pasado en diálogo con obras de estas activistas, de estos grupos de mujeres. Fue una muestra que combinaba fotografía, con obras de arte contemporáneo, con documentos...

DD: ¿Sabes? Me quedé pensando si tú has visto algunas intervenciones que han hecho grupos de artistas en Ciudad Juárez, retomando la experiencia del "Siluetazo"11, siendo como una relectura del "Siluetazo", pero en esta ocasión para hablar sobre el problema del género y de los feminicidios en Ciudad Juárez.

LM: Absolutamente y me quedé fascinada con ese trabajo. Sí, absolutamente. Acá se está agitando el tema de Marita Verón y el tema de la trata ${ }^{12}$. Mujeres artistas que están trabajando con eso haciendo esténcil. A esto me refería cuando te decía que no importa tanto la recuperación hoy de la discusión al interior del canon sino más bien salirse hacia estos lugares de intervención nuevos.

\section{NOTAS}

1. Roszika Parker y Griselda Pollock, Old Mistresses. Women Art and Ideology. Lóndres y Nueva York, I.B. Tauris y Co. Ltd., 2013 (1981).

2. Se refiere al Coloquio Internacional de Historia del Arte que organizó Rita Eder cuando era directora del Instituto de Investigaciones Estéticas en 1993. Se trató de un coloquio muy grande realizado conjuntamente con el Comité International d'Historie de l'Art en la ciudad de Zacatecas, México. Las memorias se publicaron en 3 volúmenes.

3. Véase http://www.pagina12.com.ar/diario/suplementos/radar/9-503-2002-12-05.html $(2 / 7 / 2013)$

4. Véase http://www.cadadiaunfotografo.com/2010/04/adriana-lestido.html (3/7/2013)

5. Véase http://www.vidayovanovich.com/ (3/7/2013)

6. Gertrud Louise Goldschmidt (Hamburgo, 1912-Caracas, 1994)

7. Gloria Cortés Aliaga, Modernas. Santiago de Chile, Origo Ed., 2013. Ana Paula Simioni, Profissao Artista. Pintoras e escultoras académicas brasileiras. Sao Paulo, FAPESP, 2008.

8. Alejandra Niedermaier, La mujer y la fotografía. Una imagen espejada de autoconstrucción y construcción de la historia. Buenos Aires, Leviatán, 2008.

9. Se trata de la instalación de la artista argentina Nicola Costantino para el pabellón de

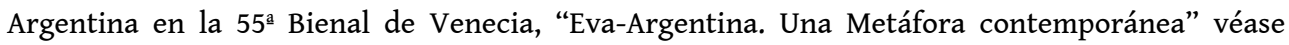
http://jaquealarte.com/2013/05/29/desde-venecia-nicola-costantino-dice-no-quiero-decir-deeva-lo-que-ya-se-dijo-mil-veces/ (2/7/2013)

10. Segundo Simposio Internacional "American Photography North and South : Comparative perspectives" organizado por la Maestría en Historia del Arte Argentino y Latinoamericano del 
Instituto de Altos Estudios Sociales (IDAES) de la Universidad Nacional de San Martín (UNSAM), con el apoyo de Terra Foundation, Buenos Aires, 22 y 23 de mayo de 2013

11. Sobre el Siluetazo, ver textos de Ana Longoni y Gustavo Bruzzone http:// hemisphericinstitute.org/hemi/es/e-misferica-72/fassi y también http:// www.macromuseo.org.ar/colecc... (26/08/2013)

12. Caso muy conocido sobre la trata de mujeres en la Argentina. http://es.wikipedia.org/wiki/ Caso_Marita_Ver\%C3\%B3n (1/7/2013) y http://www.pagina12.com.ar/diario/elpais/ 1-187794-2012-02-17.html ((1/7/2013)

\section{RESÚMENES}

Laura Malosetti es reconocida a nivel internacional como una Historiadora del Arte Argentino y Latinoamericano con una trayectoria importantísima en los estudios de género. Laura Malosetti es doctora en filosofía y Letras con orientación en Historia del Arte por la Universidad de Buenos Aires desde el año 2000. Su tesis doctoral "Imágenes para un proyecto de civilización. Condiciones de la producción artística en Buenos Aires (1876-1896)" fue dirigida por el Dr. José Emilio Burucúa. La Dra. Malosetti es actualmente Investigadora principal del CONICET (Consejo Nacional de Investigaciones Científicas y Técnicas), directora de la Maestría en Historia del Arte Argentino y Latinoamericano en el Instituto de Altos Estudios Sociales (IDAES) de la Universidad Nacional General San Martín donde además es profesora titular de la cátedra de "Problemas del arte argentino y latinoamericano del siglo XIX". Es miembro del Centro Argentino de Investigadores en Artes (CAIA), de la Asociación Internacional de Críticos de Arte (AICA),el International Association for Word and Image Studies (IAWIS) y de la Association for Latin American Art (ALAA). A participado como integrante y directora de numerosos proyectos subsidiados en la Universidad de Buenos Aires (UBACYT) y la Fundación Getty entre otros. Autora de varios libros y artículos sobre arte argentino y latinoamericano, entre ello: Los primeros modernos. Arte y sociedad en Buenos Aires a Fines del siglo XIX (FCE), Cuadros de viaje (FCE) y Collivadino (El Ateneo). Co-editora de Arte de posguerra. Jorge Romero Brest y la revista Ver y Estimar y de Impresiones Porteñas. Imagen y palabra en la historia cultural de Buenos Aires. Investigadora visitante en las Universidades de Leeds y de East Anglia (UK), de la Ecole des Hautes Etudes en Sciences Sociales y del Institut Nationale d'Histoire de l'Art (Paris); Profesora visitante de la Freie Universität de Berlín, Université de Paris Creteuil y la Universidad Nacional Autónoma de México, entre otras.

\section{ÍNDICE}

Palabras claves: Laura Malosetti, Historia del Arte Argentina, Historia del Arte Latinoamericana, estudios de género.

\section{AUTORES}

\section{DEBORAH DOROTINSKY ALPERSTEIN}

Instituto de Inv. Estéticas Universidad Nacional Autónoma de México 